\title{
Role of monocyte to high-density lipoprotein cholesterol ratio in predicting left atrial enlargement in hypertensive patients
}

\author{
Aziz Inan Celik [1], Muhammet Bugra Karaaslan²* (1)
}

\begin{abstract}
SUMMARY
OBJECTIVE: Left atrium enlargement is common in hypertension due to left atrium inflammation. Monocyte to high-density lipoprotein cholesterol ratio, an inflammation marker that has become very popular in recent years, is associated with many cardiovascular diseases. The aim of this study is to investigate the monocyte to high-density lipoprotein cholesterol ratio level to predict the Left atrium enlargement in hypertensive patients.

METHODS: A total of 216 participants (i.e., 115 hypertensive and 101 control group) were enrolled. Left atrial volumes and left atrial volume indexes were calculated using transthoracic echocardiography. The monocyte to high-density lipoprotein cholesterol ratio was calculated as the ratio of monocyte to high-density lipoprotein cholesterol levels.

RESULTS: The left atrial volumes, left atrial volume indexes, and monocyte to high-density lipoprotein cholesterol levels were significantly higher in the hypertensive group than in the control group $(43.3 \pm 12.4$ versus $31.4 \pm 7.9, p<0.001 ; 22.9 \pm 5.8$ versus $17.1 \pm 3.7, p<0.001$; 11.4 [4.2-25.0] versus 8.4 [3.5-18.0], $p<0.001$, respectively). On the multivariate logistic regression analysis, monocyte to high-density lipoprotein cholesterol ratio (OR 1.38; $95 \% \mathrm{Cl} 1.20-1.57 ; \mathrm{p}<0.001),(\mathrm{OR} 1.28 ; 95 \% \mathrm{Cl} 1.16-1.42 ; \mathrm{p}<0.001)$, age, and sex (female) were the independent predictors for hypertension.

CONCLUSIONS: The increased monocyte to high-density lipoprotein cholesterol ratio level was associated with hypertension and increased left atrial volume indexes. The results of this study supported the presence of inflammation, measured with a readily available and inexpensive marker, in hypertensive patients and revealed the association with left atrial enlargement.

KEYWORDS: Hypertension. Inflammation. Left atrium. Monocytes. High-density lipoprotein.
\end{abstract}

\section{INTRODUCTION}

Hypertension (HT) is a significant and common risk factor for cardiovascular diseases worldwide 1 . Endothelial dysfunction and an increase in oxidative stress due to increased cardiac output and peripheral vascular resistance cause damage to cardiac and vascular tissues ${ }^{2,3}$. This increased oxidative stress and endothelial dysfunction stimulate inflammatory cells to secrete many cytokines ${ }^{4}$. Left atrium (LA) remodeling and enlargement are seen in patients with HT due to both an increase in LA pressure and inflammation ${ }^{5}$. The LA enlargement is associated with atrial fibrillation, stroke, cardiovascular events, and mortality ${ }^{6}$.
Monocytes are the primary cells of the inflammatory response?. Monocytes play an essential role in the first stage of inflammation by binding to adhesion molecules expressed on the damaged endothelium ${ }^{8}$. High-density lipoprotein cholesterol (HDL-C) is involved in transferring excess cholesterol from peripheral regions to the liver. The biological activity of HDL includes antioxidant, anti-inflammatory, antithrombotic, and anti-atherosclerotic effects, and these conditions demonstrate positive effects on cardiovascular outcomes? In recent years, the monocyte to HDL-C ratio (MHR) is a new and widely used inflammation and oxidative stress marker and is calculated as the monocyte count ratio to HDL-C ratio level ${ }^{10}$.

\footnotetext{
'Gebze Fatih State Hospital, Department of Cardiology - Kocaeli, Turkey.

${ }^{2}$ Osmancik State Hospital, Department of Cardiology - Çorum, Turkey.

*Corresponding author: bgkaraaslan@gmail.com

Conflicts of interest: the authors declare there is no conflicts of interest. Funding: none.

Received on February 07, 2021. Accepted on March 21, 2021.
} 
In this study, we aimed to investigate the value of MHR to predict the LA enlargement in hypertensive patients.

\section{METHODS}

\section{Study population}

A total of 216 participants, of whom 115 were hypertensive and 101 were controls, were included in this prospective study. HT is defined as office systolic blood pressure of $\geq 140 \mathrm{~mm} \mathrm{Hg}$, a diastolic blood pressure of $\geq 90 \mathrm{~mm} \mathrm{Hg}$, and patients receiving hypertensive treatment were included in the study. Blood pressure was measured according to the $2018 \mathrm{ESC} / \mathrm{ESH}$ clinical practice guidelines for the management of arterial hypertension $^{11}$. The measurements, such as sex, age, body surface area (BSA, the Du Bois formulation, $\mathrm{m}^{2}$ ), body mass index (BMI, $\mathrm{kg} / \mathrm{m}^{2}$ ), HT, diabetes mellitus (DM), smoking status, medications, lipid panels, MHR, and transthoracic echocardiography (TTE), included in this study were recorded. Patients with $\leq 18$ years old and history of coronary artery disease, atrial fibrillation, malignancies, acute or chronic inflammatory or autoimmune disease, acute or chronic infectious disease, heart failure with reduced ejection fraction, moderate/severe valve stenosis or insufficiency, chronic liver failure (alanine transaminase [ALT] and aspartate transaminase [AST] levels higher than threefold of normal levels), and chronic kidney disease (Cockcroft-Gault, glomerular filtration rate $[\mathrm{GFR}]<60 \mathrm{~mL} / \mathrm{min} / 1.73 \mathrm{~m}^{2}$ ) were excluded. The study protocol was reviewed and approved by the Local Ethics Committee and was conducted in accordance with the Declaration of Helsinki.

\section{Echocardiographic evaluation}

The transthoracic echocardiographic examinations were performed using the Vivid $S 5^{\circledR}$ cardiovascular ultrasound system (6T-RS, 5.0 MHz probe TEE GE Medical System, Norway). Left atrial volume (LAV) was calculated using the biplane arealength method by the measurements obtained from the standard views following the recommendations of the American Society of Echocardiography. In brief, LAV was calculated using the formula: $(0.85 \times \mathrm{A} 1 \times \mathrm{A} 2) /(\mathrm{L})$, where $\mathrm{A} 1$ was the maximum planimeter LA area in an apical four-chambered (A4C) view anteroposterior diameter in parasternal long axis, $\mathrm{A} 2$ was the maximum planimeter LA area in an apical two-chambered (A2C) view, and $\mathrm{L}$ was the length measured from back wall to line across mitral valve hinge points $(\mathrm{cm})$. Left atrial volume index (LAVI) was calculated by dividing the LAV by the body surface area.

\section{Blood sample analyses}

Peripheral venous blood samples were obtained from the patients on their admission. An automated blood cell counter (Beckman Coulter analyzer, California, USA) was used for measuring complete blood count $(\mathrm{CBC})$ parameters, and $\mathrm{CBC}$ samples were collected in ethylenediaminetetraacetic acid (EDTA)-anticoagulated Monovette ${ }^{\circledR}$ tubes (Sarstedt). Monocyte count was calculated from the $\mathrm{CBC}$ analysis. The biochemical parameters, such as total cholesterol, HDL-C, low-density lipoprotein cholesterol (LDL-C), and triglyceride levels, were also measured. The MHR was calculated as the ratio of monocytes to HDL-C levels.

\section{Statistical analysis}

Descriptive statistics were given as mean \pm standard deviation and median with minimum-maximum values for continuous variables depending on their distribution. Numbers and percentages were used for categorical variables. The normal distribution of numerical variables was analyzed by using the Kolmogorov-Smirnov test due to the sample size being greater than 50 and was checked by Q-Q plots and histograms. In comparing the two independent groups, the Independent Samples $t$-test was used where the numerical variables had a normal distribution. For variables without normal distribution, the Mann-Whitney U test was applied. To compare the differences between categorical variables, the Pearson's $\chi^{2}$ and Fisher's exact tests were used in $2 \times 2$ tables. The Spearman's and Pearson's correlation coefficients were calculated to analyze the relationships between MHR and LAV with demographic and clinical variables. The univariate normality and multivariate multicollinearity with correlation coefficients and the variance inflation factor between the variables were used to deal with the collinearity problems before univariate and multivariate linear regression analyses. Univariate and multivariate logistic regression analyses were used for the determination of independent risk factors for HT. For statistical analysis and figures, Microsoft Office Excel and the "jamovi" project (2020), the jamovi software (version 1.2.24; retrieved from https://www. jamovi.org), and the JASP software (version 0.13.1; retrieved from https://jasp-stats.org) were used. The significance level (p-value) was set at 0.05 in all the statistical analyses.

\section{RESULTS}

There were a total of 216 patients in the study group. HT was present in 115 patients $(53.2 \%)$. The mean age of the patients with HT was significantly higher (53.1 versus 44.8 years) 
$(\mathrm{p}<0.001)$. There were considerably more nonsmokers in the hypertensive group ( $\mathrm{p}=0.048$ ). The median BMI was $31.2 \mathrm{~kg} /$ $\mathrm{m}^{2}$ in the HT group, and it was significantly higher than that in the control group $(\mathrm{p}<0.001)$. The mean LAV was significantly higher in patients with HT (43.3 versus $31.4 \mathrm{~mL})(\mathrm{p}<0.001)$. The mean LAVI was 22.9 and $17.1 \mathrm{~mL} / \mathrm{m}^{2}$ in patients with and without HT, respectively. This difference was statistically significant $(\mathrm{p}<0.001)$.

The MHR was significantly higher in hypertensive patients than in those without HT $(\mathrm{p}<0.001)$. The median value was
11.4 in the HT group, while it was 8.4 in the control group. There were no significant differences in sex distribution, DM, alcohol use, and laboratory values except for MHR between the groups. The demographic and clinical features of the study are summarized in Table 1.

The correlation analysis revealed significant associations between MHR and other variables (Table 2). Age and BSA were positively correlated with MHR ( $r=0.143 ; \mathrm{p}=0.036$ and $\mathrm{r}=0.198 ; \mathrm{p}=0.004$, respectively). In the study group, MHR showed direct correlations to LAV and LAVI $(r=0.248 ; \mathrm{p}<0.001$

Table 1. Demographic and clinical features of the study group.

\begin{tabular}{|c|c|c|c|c|}
\hline & $\begin{array}{l}\text { Overall } \\
(n=216)\end{array}$ & $\begin{array}{l}\text { Hypertension group } \\
\qquad(n=115)\end{array}$ & $\begin{array}{l}\text { Control group } \\
(n=101)\end{array}$ & p-value \\
\hline Age (year)a & $49.2 \pm 9.2$ & $53.1 \pm 7.7$ & $44.8 \pm 8.7$ & $<0.001 *$ \\
\hline \multicolumn{5}{|l|}{ Sex ${ }^{b}$} \\
\hline Female & $140(64.8)$ & $79(68.7)$ & $61(60.4)$ & $0.258^{* * *}$ \\
\hline Male & $76(35.2)$ & 36 (31.3) & $40(39.6)$ & \\
\hline Diabetes mellitusb & $13(6.0)$ & $9(7.8)$ & $4(4.0)$ & $0.365^{* * *}$ \\
\hline \multicolumn{5}{|l|}{ Smoking ${ }^{b}$} \\
\hline Nonsmoker & $136(63.0)$ & $80(69.6)$ & $56(55.4)$ & $0.048^{* * *}$ \\
\hline Ex-smoker & $35(16.2)$ & $18(15.7)$ & $17(16.8)$ & \\
\hline Active smoker & $45(20.8)$ & $17(14.8)$ & $28(27.7)$ & \\
\hline $\begin{array}{l}\text { Alcohol } \\
\text { consumption }^{\mathrm{b}}\end{array}$ & $1(0.5)$ & $0(0.0)$ & $1(1.0)$ & $0.468 * * *$ \\
\hline BMI $\left(\mathrm{kg} / \mathrm{m}^{2}\right)^{\mathrm{c}}$ & $29.4(16.5-46.2)$ & $31.2(19.4-46.2)$ & $28.3(16.5-45.5)$ & $<0.001$ ** \\
\hline $\operatorname{BSA}\left(\mathrm{m}^{2}\right)^{\mathrm{a}}$ & $1.9 \pm 0.2$ & $1.9 \pm 0.2$ & $1.8 \pm 0.2$ & $0.030 *$ \\
\hline $\operatorname{LAV}(\mathrm{mL})^{a}$ & $37.8 \pm 12.1$ & $43.3 \pm 12.4$ & $31.4 \pm 7.9$ & $<0.001 *$ \\
\hline LAVI $\left(\mathrm{mL} / \mathrm{m}^{2}\right)^{\mathrm{a}}$ & $20.2 \pm 5.7$ & $22.9 \pm 5.8$ & $17.1 \pm 3.7$ & $<0.001 *$ \\
\hline Cholesterol $(\mathrm{mg} / \mathrm{dL})^{c}$ & $175.5(112.0-310.0)$ & $177.0(123.0-310.0)$ & $170.0(112.0-290.0)$ & $0.117^{* \star}$ \\
\hline $\operatorname{LDL}(\mathrm{mg} / \mathrm{dL})^{c}$ & $121.0(76.0-231.0)$ & $123.0(84.0-231.0)$ & $118.0(76.0-206.0)$ & $0.118^{* *}$ \\
\hline Triglyceride (mg/dL)a & $178.3 \pm 48.3$ & $177.9 \pm 55.1$ & $178.8 \pm 39.5$ & $0.891 *$ \\
\hline $\mathrm{HDL}(\mathrm{mg} / \mathrm{dL})^{c}$ & $37.0(24.0-74.0)$ & $37.0(24.0-74.0)$ & $38.0(28.0-74.0)$ & $0.776^{* *}$ \\
\hline $\mathrm{MHR}^{c}$ & $10.0(3.5-25.0)$ & $11.4(4.2-25.0)$ & $8.4(3.5-18.0)$ & $<0.001$ ** \\
\hline $\begin{array}{l}\text { Use of at least one } \\
\text { drug }^{\text {b }}\end{array}$ & $57(26.4)$ & 57 (49.6) & - & N/A \\
\hline \multicolumn{5}{|l|}{ Antihypertensive drugs $^{b}$} \\
\hline ACE inhibitor & $22(10.2)$ & $22(19.1)$ & - & N/A \\
\hline ARB & $26(12.0)$ & $26(22.6)$ & - & N/A \\
\hline$C C B$ & $29(13.4)$ & $29(25.2)$ & - & N/A \\
\hline Diuretics & $29(13.4)$ & $29(25.2)$ & - & N/A \\
\hline Beta blocker & $6(2.8)$ & $6(5.2)$ & - & N/A \\
\hline
\end{tabular}

BMI: body mass index; BSA: body surface area; LAV: left atrial volume; LAVI: left atrial volume index; LDL: low-density lipoprotein; HDL: high-density lipoprotein; MHR: monocyte-to-HDL-C ratio; ACE: angiotensin-converting enzyme; ARB: angiotensin-II receptor blocker; CCB: calcium-channel blocker.

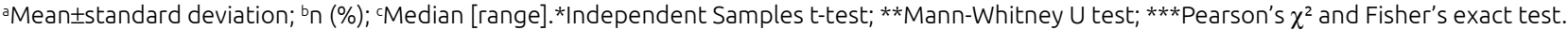


and $\mathrm{r}=0.177 ; \mathrm{p}=0,009$, respectively). Among the laboratory values, total cholesterol, triglyceride, and HDL were also significantly associated with MHR ( $\mathrm{p}<0.05$ for all), while the correlation between MHR and HDL did not reach the statistical significance $(\mathrm{p}=0.665)$ (Table 2$)$.

In Table 3, univariate and multivariate regression analyses for HT are detailed. Univariate and multivariate regression analyses were employed to identify the independent risk factors of HT. Age (OR 1.13; 95\%CI 1.09-1.18; $\mathrm{p}<0.001)$, active smoking (OR 0.42; 95\%CI 0.21-0.85; $\mathrm{p}=0.015)$, BMI (OR 1.12; 95\%CI 1.06-1.18; $\mathrm{p}<0.001)$, LAVI (OR 1.31; 95\%CI 1.21-1.42; $\mathrm{p}<0.001$ ), and MHR (OR 1.27; 95\%CI 1.15-1.40; $\mathrm{p}<0.001)$ were the significant independent risk factors. In the multivariate analysis, sex was found to be an independent risk factor beside age (OR 1.10; 95\%CI 1.04-1.16; $\mathrm{p}<0.001$ ), LAVI (OR 1.28; 95\%CI 1.16-1.42; $\mathrm{p}<0.001$ ), and MHR (OR 1.38; $95 \% \mathrm{CI} 1.20-1.57, \mathrm{p}<0.001)$. Female sex increased the risk for HT incidence by 2.88 -fold, with $95 \% \mathrm{CI} 1.10-7.54$ ( $\mathrm{p}=0.031$ ).

To determine the cutoff value, the receiver operating characteristic curve (ROC curve) analysis using the sensitivity, specificity, and Youden's index based on the diagnosis of HT revealed that the optimal cutoff value for MHR was 9.2 (i.e., sensitivity of $77.39 \%$ and specificity of $63.37 \%$; area under the curve AUC 0.711; 95\%CI 0.646-0.770; $\mathrm{p}<0.001$ ).

Table 2. Correlation analysis of monocyte to high-density lipoprotein cholesterol ratio with demographic features and laboratory findings.

\begin{tabular}{l|c|c}
\multirow{2}{*}{ Age } & \multicolumn{2}{|c}{ MHR } \\
\cline { 2 - 3 } & Rho & p-value \\
\hline BMI $\left(\mathrm{kg} / \mathrm{m}^{2}\right)$ & 0.143 & $0.036^{*}$ \\
\hline BSA $\left(\mathrm{m}^{2}\right)$ & 0.121 & $0.077^{* *}$ \\
\hline LAV $(\mathrm{mL})$ & 0.198 & $0.004^{* *}$ \\
\hline LAVI $\left(\mathrm{mL} / \mathrm{m}^{2}\right)$ & 0.248 & $<0.001^{* *}$ \\
\hline Total cholesterol $(\mathrm{mg} / \mathrm{dL})$ & 0.177 & $0.009^{* *}$ \\
\hline LDL-C $(\mathrm{mg} / \mathrm{dL})$ & -0.143 & $0.036^{* *}$ \\
\hline Triglyceride $(\mathrm{mg} / \mathrm{dL})$ & -0.034 & $0.618^{* *}$ \\
\hline HDL-C $(\mathrm{mg} / \mathrm{dL})$ & 0.154 & $0.024^{*}$ \\
\hline
\end{tabular}

MHR: monocyte to HDL-C ratio; Rho: Spearman's rank correlation coefficient; BMI: body mass index; BSA: body surface area; LAV: left atrial volume; LAVI: left atrial volume index; LDL-C: low-density lipoprotein cholesterol; HDL-C: high-density lipoprotein cholesterol. *Pearson's r; **Spearman's rho.

Table 3. Univariate and multivariate regression analysis for the development of hypertension.

\begin{tabular}{|c|c|c|c|c|}
\hline & \multicolumn{2}{|c|}{$\begin{array}{c}\text { Model for univariate } \\
\text { logistic regression analysis }\end{array}$} & \multicolumn{2}{|c|}{$\begin{array}{c}\text { Model for multivariate } \\
\text { logistic regression analysis }\end{array}$} \\
\hline & OR $(95 \% \mathrm{Cl})$ & p-value & OR $(95 \% \mathrm{Cl})$ & p-value \\
\hline Age & $1.13(1.09-1.18)$ & $<0.001$ & $1.10(1.04-1.16)$ & $<0.001$ \\
\hline Sex (female versus male) & $1.44(0.82-2.52)$ & 0.203 & $2.88(1.10-7.54)$ & 0.031 \\
\hline \multicolumn{5}{|l|}{ Smoking } \\
\hline Ex-smoker & $0.74(0.35-1.56)$ & 0.431 & $1.27(0.38-4.16)$ & 0.698 \\
\hline Smoker & $0.42(0.21-0.85)$ & 0.015 & $0.41(0.13-1.23)$ & 0.111 \\
\hline BMI & $1.12(1.06-1.18)$ & $<0.001$ & $1.06(0.98-1.15)$ & 0.119 \\
\hline LAVI & $1.31(1.21-1.42)$ & $<0.001$ & $1.28(1.16-1.42)$ & $<0.001$ \\
\hline MHR & $1.27(1.15-1.40)$ & $<0.001$ & $1.38(1.20-1.57)$ & $<0.001$ \\
\hline
\end{tabular}

OR: odds ratio; Cl: confidence interval; BMI: body mass index; LAVI: left atrial volume index; MHR: monocyte-to-HDL-C ratio. 


\section{DISCUSSION}

In this study, the LA volume changes (i.e., LAV and LAVI) in HT patients were measured. The relationship of MHR, a biomarker showing especially inflammation in recent years, with both HT and LA volume changes was examined. At the end point, LAV, LAVI, and MHR levels were significantly higher in HT patients than in the control group. A significant correlation was found between the MHR level and LA volumes.

In patients with HT, LA length, surface area, and volume significantly increased compared with those in the control group patients. In the population-based studies, $27 \%$ of individuals with HT found an enlargement in LAVI ${ }^{12}$. The LA passive emptying decreases as a result of left ventricular (LV) diastolic dysfunction observed in patients with HT, and LA (i.e., LAV and LAVI) pressures and volumes increase ${ }^{13}$. Endothelial dysfunction and increased oxidative stress due to increased cardiac flow and peripheral vascular resistance damage the cardiac and vascular tissues by enhancing inflammation ${ }^{14}$. LA remodeling and enlargement are seen in patients with HT due to both increases in LA pressure and triggering of inflammation ${ }^{5}$.

Inflammation has an essential role in the progression of atherosclerosis and cardiovascular diseases. Monocytes are critical in the occurrence of inflammation. Monocytes are activated by binding to adhesion molecules expressed on the damaged endothelium and play an essential role in the first step of atherosclerosis progression ${ }^{15}$. Activated monocytes migrate to the subendothelial region and develop into macrophages. Macrophages become foam cells by phagocytosing the oxidized LDL-C molecules, and these foam cells secrete pro-inflammatory and pro-oxidant cytokines ${ }^{16}$.

Contrary to the effects of monocytes described earlier, HDL-C decreases monocyte activation and adhesion, regulates endothelial adhesion molecules' release, reverses the effects of oxidized LDL$\mathrm{C}$, and causes vasodilation by $\mathrm{NO}$ release ${ }^{17}$. This anti-inflammatory effect of HDL-C reduces the risk of cardiovascular events ${ }^{18}$. The increased levels of pro-inflammatory monocytes and low anti-inflammatory HDL-C are indirect indicators of inflammation. In recent years, many studies have found that the MHR is a marker of inflammation and prognosis in many cardiovascular events. Akboga et al. revealed that high SYNTAX score and MHR were interrelated in patients with stable angina pectoris ${ }^{19}$. A study conducted by Cetin et al. found that the Gensini and SYNTAX scores and MHR levels were positively correlated with the severity of coronary artery disease and had an independent correlation with future cardiovascular events such as acute coronary syndrome ${ }^{20}$.

In this study, LAV, LAVI, and MHR were significantly higher in hypertensive patients than in the control group. Also, a significant positive correlation between MHR and LAV and LAVI was found. In reviewing the current literature, this is the first study that examined the relationship between MHR and LA volumes in hypertensive patients. It is known that the enlargement in LA volumes causes many cardiovascular end points (i.e., atrial fibrillation, stroke, etc.) in HT. This study showed that the increased MHR levels revealed the inflammation in HT patients, and also, this marker is overwhelmingly associated with LA volume changes.

This study has several limitations. First, the 2D-TTE was used, while the measurements could be performed more precisely using the real-time 3D-TTE or cardiac MRI. Second, the study was single centered, and a relatively lower number of patients were included. Third, the specific inflammatory markers, such as high-sensitivity C-reactive protein (hs-CRP), tumor necrosis factor- $\alpha$ (TNF- $\alpha$ ), interleukin- 6 (IL-6), and neutrophil to lymphocyte ratio, were not measured.

\section{CONCLUSIONS}

Our study demonstrated that MHR was significantly correlated with LAV and LAVI in hypertensive patients. The MHR is a low-cost and straightforward biochemical marker that shows inflammation in LA remodeling. Further prospective studies are needed to evaluate the association between MHR and LAV.

\section{AUTHORS" CONTRIBUTIONS}

AIC: Conceptualization, Data curation, Methodology, Writingreview \& editing. MBK: Conceptualization, Project administration, Supervision, Writing - original draft, Writing - review \& editing.

\section{REFERENCES}

1. Kannel WB. Blood pressure as a cardiovascular risk factor: prevention and treatment. JAMA. 1996;275(20):1571-6. https://doi.org/10.1001/jama.1996.03530440051036

2. Lackland DT. Controlling hypertension to prevent target organ damage: perspectives from the World Hypertension League President. Ethn Dis. 2016;26(3):267-70. https://doi. org/10.18865/ed.26.3.267

3. Panza JA, Quyyumi AA, Brush JE Jr, Epstein SE. Abnormal endothelium-dependent vascular relaxation in patients with essential hypertension. N Engl J Med. 1990;323(1):22-7. https://doi.org/10.1056/NEJM199007053230105

4. Dinh QN, Drummond GR, Sobey CG, Chrissobolis S. Roles of inflammation, oxidative stress, and vascular dysfunction in hypertension. Biomed Res Int. 2014;2014:406960. https:// doi.org/10.1155/2014/406960

5. Matsuda M, Matsuda Y. Mechanism of left atrial enlargement related to ventricular diastolic impairment in hypertension. Clin Cardiol. 1996;19(12):954-9. https://doi.org/10.1002/clc.4960191211 
6. Kizer JR, Bella JN, Palmieri V, Liu JE, Best LG, Lee ET, et al. Left atrial diameter as an independent predictor of first clinical cardiovascular events in middle-aged and elderly adults: The Strong Heart Study (SHS). Am Heart J. 2006;151(2):412-8. https://doi.org/10.1016/j.ahj.2005.04.031

7. Kundi H, Kiziltunc E, Cetin M, Cicekcioglu H, Cetin ZG, Cicek $\mathrm{G}$, et al. Association of monocyte/HDL-C ratio with SYNTAX scores in patients with stable coronary artery disease. Herz. 2016;41(6):523-9. https://doi.org/10.1007/s00059-015-4393-1

8. Tani S, Matsumoto M, Anazawa T, Kawamata H, Furuya S, Takahashi $\mathrm{H}$, et al. Development of a model for prediction of coronary atherosclerotic regression: evaluation of highdensity lipoprotein cholesterol level and peripheral blood monocyte count. Heart Vessels. 2012;27(2):143-50. https:// doi.org/10.1007/s00380-011-0130-8

9. Ganjali S, Momtazi AA, Banach M, Kovanen PT, Stein EA, Sahebkar A. HDL abnormalities in familial hypercholesterolemia: focus on biological functions. Prog Lipid Res. 2017;67:16-26. https://doi.org/10.1016/j.plipres.2017.05.001

10. Canpolat U, Çetin EH, Cetin S, Aydin S, Akboga MK, Yayla $C$, et al. Association of monocyte-to-HDL cholesterol ratio with slow coronary flow is linked to systemic inflammation. Clin Appl Thromb Hemost. 2016;22(5):476-82. https://doi. org/10.1177/1076029615594002

11. Williams B, Mancia G, Spiering W, Agabiti Rosei E, Azizi M, Burnier M, et al. 2018 ESC/ESH Guidelines for the management of arterial hypertension: The Task Force for the management of arterial hypertension of the European Society of Cardiology (ESC) and the European Society of Hypertension (ESH). J Hypertens. 2018;36(10):1953-2041. https://doi.org/10.1097/ HJH.0000000000001940

12. Pritchett AM, Jacobsen SJ, Mahoney DW, Rodeheffer RJ, Bailey $\mathrm{KR}$, Redfield MM. Left atrial volume as an index of left atrial size: a population-based study. J Am Coll Cardiol. 2003;41(6):103643. https://doi.org/10.1016/s0735-1097(02)02981-9
13. Eshoo S, Ross DL, Thomas L. Impact of mild hypertension on left atrial size and function. Circ Cardiovasc Imaging. 2009;2(2):93-9. https://doi.org/10.1161/CIRCIMAGING.108.793190

14. Dinh QN, Drummond GR, Sobey CG, Chrissobolis S. Roles of inflammation, oxidative stress, and vascular dysfunction in hypertension. Biomed Res Int. 2014;2014:406960. https:// doi.org/10.1155/2014/406960

15. Tani S, Matsumoto M, Anazawa T, Kawamata H, Furuya S, Takahashi $\mathrm{H}$, et al. Development of a model for prediction of coronary atherosclerotic regression: evaluation of highdensity lipoprotein cholesterol level and peripheral blood monocyte count. Heart Vessels. 2012;27(2):143-50. https:// doi.org/10.1007/s00380-011-0130-8

16. Ghattas A, Griffiths HR, Devitt A, Lip GY, Shantsila E. Monocytes in coronary artery disease and atherosclerosis: where are we now? J Am Coll Cardiol. 2013;62(17):1541-51. https://doi. org/10.1016/j.jacc.2013.07.043

17. Murphy AJ, Chin-Dusting JP, Sviridov D, Woollard KJ. The anti inflammatory effects of high density lipoproteins. Curr Med Chem. 2009;16(6):667-75. https://doi.org/10.2174/092986709787458425

18. Tardif JC, Grégoire J, L'Allier PL, Ibrahim R, Lespérance J, Heinonen $T M$, et al. Effects of reconstituted high-density lipoprotein infusions on coronary atherosclerosis: a randomized controlled trial. JAMA. 2007;297(15):1675-82. https://doi.org/10.1001/ jama.297.15.jpc70004

19. Akboga MK, Balci KG, Maden O, Ertem AG, Kirbas O, Yayla C, et al. Usefulness of monocyte to $\mathrm{HDL}$ cholesterol ratio to predict high SYNTAX score in patients with stable coronary artery disease. Biomark Med. 2016;10(4):375-83. https://doi.org/10.2217/ bmm-2015-0050

20. Cetin MS, Ozcan Cetin EH, Kalender E, Aydin S, Topaloglu S, Kisacik $\mathrm{HL}$, et al. Monocyte to HDL cholesterol ratio predicts coronary artery disease severity and future major cardiovascular adverse events in acute coronary syndrome. Heart Lung Circ. 2016;25(11):1077-86. https://doi.org/10.1016/j.hlc.2016.02.023 